\title{
Endothelial expression of intercellular adhesion molecule 1 and vascular cell adhesion molecule 1 is suppressed by postbypass plasma containing increased soluble intercellular adhesion molecule 1 and vascular cell adhesion molecule 1
}

Michael P. Vallely, MBBS ${ }^{a, b, c}$

Paul G. Bannon, FRACS, PhD ${ }^{\mathrm{b}, \mathrm{c}}$

Clifford F. Hughes, AO, FRACS ${ }^{b, c}$

Leonard Kritharides, FRACP, PhD ${ }^{a, d}$
Objective: Endothelial cell dysfunction has been implicated in the inflammatory response to cardiopulmonary bypass, and the upregulation of endothelial cell expression of adhesion molecules might promote leukocyte extravasation in vivo. Soluble endothelial cell adhesion molecules are increased after bypass. The aim of this study was to investigate the relationship between endothelial cell-surface expression of adhesion molecules and their concentration in plasma after coronary artery bypass grafting.

Methods: Ten patients undergoing coronary artery bypass with cardiopulmonary bypass had 5 plasma samples taken at defined intervals before, during, and after cardiopulmonary bypass. Plasma was incubated with human umbilical vein endothelial cell monolayers, and expression of E-selectin, intercellular adhesion molecule 1 , and vascular cell adhesion molecule 1 on the surface of human umbilical vein endothelial cell monolayers was measured by means of enzyme-linked immunosorbent assay. Plasma soluble adhesion molecules, C-reactive protein, interleukin 8, interleukin 10, transforming growth factor $\beta 1$, and neutrophil counts were determined for each patient.

Results: Markers typical of acute inflammation (ie, interleukin 8, neutrophils, and C-reactive protein) were all increased after bypass. Soluble plasma intercellular and vascular cell adhesion molecule 1 (but not E-selectin) were increased after bypass. However, endothelial cell expression of vascular cell adhesion molecule 1 and intercellular adhesion molecule 1 (but not E-selectin) were significantly decreased by exposure to postbypass plasma. Additionally, postbypass plasma inhibited interleukin $1 \beta$-stimulated endothelial cell expression of vascular cell and intercellular adhesion molecule 1. Interleukin 10 and transforming growth factor $\beta 1$, both of which are known to inhibit endothelial cell adhesion molecule expression, were respectively increased 10 -fold and 3 -fold $(P<.05)$ after bypass.

Conclusions: Despite containing increased soluble intercellular and vascular cell adhesion molecule 1, postbypass plasma inhibits endothelial cell expression of intercellular and vascular cell adhesion molecule 1. Upregulated vascular expression of adhesion molecules might not be essential for endothelial activation after bypass. 


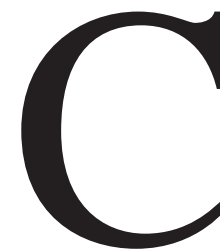

ardiopulmonary bypass (CPB) is known to cause a systemic inflammatory response syndrome, which can contribute to significant morbidity and mortality. ${ }^{1}$ The endothelial-leukocyte adhesion cascade is central to the transmigration of activated leukocytes into the subendothelial space, where they degranulate, promoting inflammatory injury. Upregulation of endothelial cell (EC) adhesion molecule expression occurs in many inflammatory conditions ${ }^{2-4}$ and promotes the adhesion and transmigration of leukocytes.

CPB has generally been associated with increased levels of plasma soluble EC adhesion molecules, which have been attributed to the activation and injury of ECs. ${ }^{1,5-7}$ However, some studies have shown a decrease in soluble adhesion molecule levels after CPB. ${ }^{8}$ Whether soluble adhesion molecules contribute to the causation of the systemic inflammatory response syndrome after bypass or are merely a marker of other inflammatory processes is unclear. Indeed, they might even have an anti-inflammatory role under some circumstances..$^{9,10}$

The relationship between soluble adhesion molecules and their endothelial expression is not well established. ${ }^{10}$ This is because adhesion molecules can be expressed on non-ECs, such as monocytes, tissue macrophages, fibroblasts, and dendritic cells, ${ }^{11-15}$ and because it is difficult to evaluate EC adhesion molecule expression in human subjects in vivo. The effect of $\mathrm{CPB}$ on EC expression of adhesion molecules might be important for therapeutic targeting of the post-CPB inflammatory response and for understanding the mechanism of CPB-induced inflammation within the vascular bed.

The aim of this study was to investigate the relationship between EC surface expression of adhesion molecules and their concentration in plasma after coronary artery bypass grafting $(\mathrm{CABG})$. Although soluble intercellular adhesion molecule 1 (ICAM-1), soluble vascular cell adhesion molecule 1 (VCAM-1), and other inflammatory markers are confirmed to be increased after CPB, post-CPB plasma downregulates the expression of ICAM- 1 and VCAM- 1 on ECs. These observations dissociate the regulation of soluble and cell-surface adhesion molecules after CPB.

\section{Material and Methods}

\section{Patients}

Ten adult patients with multivessel coronary artery disease undergoing first-time elective $\mathrm{CABG}$ with $\mathrm{CPB}$ were enrolled in the study. The study was undertaken with institutional ethics committee approval, and written informed consent was obtained from each patient. Patients taking corticosteroids, nonsteroidal anti-inflammatory drugs, aspirin, or other immunosuppressing agents were excluded, as were patients with diabetes mellitus, renal failure, or other immunocompromising conditions. Patients receiving intravenous nitrates or heparin were also excluded.
TABLE 1. Plasma sample collection protocol

\begin{tabular}{|c|c|c|}
\hline Sample & Time/description & Location \\
\hline Before CPB & $\begin{array}{l}\text { Before CPB, after } \\
\text { systemic heparinization }\end{array}$ & Radial artery catheter \\
\hline Ischemia & $\begin{array}{l}\text { During } \mathrm{CPB} \text {, before } \mathrm{AXC} \\
\text { release (ischemia) }\end{array}$ & CPB arterial line \\
\hline Reperfusion & $\begin{array}{l}\text { During } \mathrm{CPB} \text {, after } \mathrm{AXC} \\
\text { release }\end{array}$ & Left atrium \\
\hline $\begin{array}{l}3 \mathrm{~h} \text { after } \\
24 \mathrm{~h} \text { after }\end{array}$ & $\begin{array}{l}3 \mathrm{~h} \text { postoperatively } \\
24 \mathrm{~h} \text { postoperatively }\end{array}$ & $\begin{array}{l}\text { Radial artery catheter } \\
\text { Radial artery catheter }\end{array}$ \\
\hline
\end{tabular}

$A X C$, Aortic crossclamp.

\section{Anesthetic, CPB, and Operative Techniques}

Anesthesia induction was performed with 15 to $30 \mu \mathrm{g} / \mathrm{kg}$ fentanyl, 0.5 to $1 \mathrm{mg} / \mathrm{kg}$ thiopentone, and $0.15 \mathrm{mg} / \mathrm{kg}$ pancuronium. Anesthesia was maintained with a volatile agent (isoflurane) throughout the procedure (on and off CPB). No protease inhibitors (aprotinin), antifibrinolytic agents (aminocaproic acid), or corticosteroids were used in any patients.

Standard systemic heparinization was used (400 IU/kg), and an activated clotting time of greater than 450 seconds was maintained during $\mathrm{CPB}$. CPB was performed with mild-to-moderate hypothermia $\left(30^{\circ} \mathrm{C}-32^{\circ} \mathrm{C}\right)$. The extracorporeal circuit consisted of a roller pump (Jostra), a membrane oxygenator (Capiox SX18, Terumo), and polyvinyl chloride circuit tubing (Cardio-Research) primed with $2500 \mathrm{~mL}$ of isotonic Compound Sodium Lactate solution (Hartmann's solution, Baxter) and 10,000 IU of sodium heparin.

Antegrade cold-blood cardioplegic solution (St Thomas Hospital solution) was used to arrest the heart in diastole. Myocardial protection was maintained with intermittent cold-blood cardioplegic solution (through aortic root and grafts), ice-cold saline topical cooling, and left ventricular venting (through the aortic root or right superior pulmonary vein).

An in situ, pedicled, left internal thoracic artery graft to the left anterior descending artery was used in all patients $(n=10)$. Other conduits used were aortocoronary long saphenous vein $(n=8)$, left radial artery $(\mathrm{n}=3)$, and in situ, pedicled, right internal thoracic artery grafts $(\mathrm{n}=1)$.

\section{Sample Collection and Storage}

Blood samples were taken from the indwelling radial artery catheter to evaluate factors important in systemic EC activation unless otherwise indicated (Table 1). In addition, left atrial blood was sampled to most accurately detect inflammatory mediators arising from pulmonary reperfusion. ${ }^{16}$ All samples were therapeutically heparinized (CPB heparin or $5 \mathrm{IU} / \mathrm{mL}$ ) and contained $0.58 \%$ citrate phosphate dextrose. Samples were kept on ice and then centrifuged at $3000 \mathrm{rpm}$ for 30 minutes at $4^{\circ} \mathrm{C}$, and plasma was removed and stored at $-80^{\circ} \mathrm{C}$ in $1.5-\mathrm{mL}$ cryotubes (Sarstedt) until analysis. Hemodilution during CPB was quantified by assaying plasma protein for each sample. Plasma cytokines and levels of soluble adhesion molecules were corrected for plasma protein and normalized to that of pre-CPB (control) plasma in each patient. 
TABLE 2. Clinical characteristics of subjects

\begin{tabular}{lc}
\hline Variables & Patients $(\mathbf{n}=\mathbf{1 0})$ \\
\hline No. of patients & 10 \\
Male/female & $6 / 4$ \\
Age (y) & $69(46-79)$ \\
CPB time (min) & $81(56-132)$ \\
AXC time (min) & $56(35-69)$ \\
Grafts & $3(2-5)$ \\
\hline
\end{tabular}

Data are given as median (range).

$A X C$, Aortic crossclamp.

\section{Human Umbilical Vein Endothelial Cell Isolation and Cultures}

Human umbilical vein endothelial cell (HUVEC) cultures were harvested by using a modified version of the technique described by Jaffe and colleagues. ${ }^{17}$ HUVECs were isolated with collagenase (Sigma) and grown to confluence in $175-\mathrm{cm}^{2}$ Falcon tissue-culture flasks (Becton Dickinson) in Medium 199 (Biosciences) containing 20\% heat-inactivated pooled human serum (CM199), 1\% Lglutamine (Biosciences), 0.5\% Endothelial Cell Growth Promoter (Starrate Pty Ltd), and penicillin-streptomycin (100 IU/0.1 mg/mL, Sigma). Cells were grown to confluence at $37^{\circ} \mathrm{C}$ in a $5 \% \mathrm{CO}_{2}$ incubator. Cells were subpassaged with 1:250 trypsin/ethylenediamine tetraacetic acid (Biosciences) into 96-well tissue-culture plates (Falcon, Becton Dickinson), at 10,000 cells/well in $100 \mu \mathrm{L}$ of media. All glassware was heat treated to ensure an endotoxinfree system, and media were made up in distilled water (Baxter) and then filtered with $0.2-\mu \mathrm{m}$ Zetapore filters (Cuno) before use. All experiments were conducted with passage 2 HUVECs.

Citrate phosphate dextrose $(0.58 \%)$ was added to all blood samples to overcome cytotoxic fibrin clot formation on the HUVEC cultures. In addition, samples were taken during systemic heparinization or, in the case of postoperative samples, heparin was added (5 IU $/ \mathrm{mL}$ ). Plasma samples for each patient were normalized for protein by means of dilution with isotonic crystalloid (containing no protein) Compound Sodium Lactate solution (Hartmann's Solution, Baxter) to account for hemodilution during bypass.

\section{HUVEC Expression of Adhesion Molecules}

By using a modified technique, as described by other investigators, ${ }^{2,4,18,19}$ HUVECs were exposed for 4 hours to $20 \%$ patient plasma and then $20 \%$ heat-inactivated pooled human serum. This allowed for maximal upregulation of adhesion molecule expression while maintaining normal cell viability. Cell viability was routinely assessed by means of lactate dehydrogenase release by monitoring EC morphology with light microscopy and preservation of cell attachment with quantification of cell protein, as previously described. ${ }^{20}$ Under the conditions described, cell viability was preserved $(90 \%-98 \%, \mathrm{n}=6)$, and cell protein was greater than $95 \%$ of control incubations in pooled, heat-inactivated serum.

After washing, cell-surface adhesion molecules were measured with specific enzyme-linked immunosorbent assays (ELISAs) at $4^{\circ} \mathrm{C}$, as described by McCrohon and colleagues. ${ }^{19}$ In brief, HUVECs were exposed to 1:1000 purified mouse anti-human monoclonal primary antibodies to CD54 (ICAM-1), CD62E (Eselectin), and CD106 (VCAM-1; Pharmingen, Becton Dickinson) in Hanks balanced salt solution containing $10 \%$ heat-inactivated pooled human serum, with an irrelevant, nonmammalian mouse IgG1 antibody used as a negative control (DAKO). After washing, cells were incubated with a sheep, anti-mouse horseradish peroxidase secondary antibody (Amersham, 1:500 dilution), and absorbance was read at 405-nm wavelength (Titertek Multiskan MCC 340, Labsystems) after addition of ABTS peroxidase substrate solution (Kirkegard and Perry Laboratories). For each subject, the patient's own pre-CPB plasma (sample 1) incubated with HUVECs was used as an internal control. Results were expressed as a percentage of the pre-CPB control (100\%) for each subject, with a mean \pm SD of quadruplicate cultures for each data point. Initial experiments established that control cultures incubated with pooled, heat-inactivated serum and cultures incubated with preCPB plasma demonstrated identical expression of adhesion molecules.

Commercially available interleukin $1 \beta$ (IL- $1 \beta$; Pharmingen, Becton-Dickinson) was used to investigate whether peri-CABG plasma modulated HUVEC response to IL- $1 \beta$. Stock solution was diluted and incubated with HUVECs at a final concentration of 1 $\mathrm{ng} / \mathrm{mL}$. Preliminary experiments established that this concentration of IL-1 $\beta$ generated maximal upregulation of adhesion molecule expression under our experimental conditions.

\section{Soluble Adhesion Molecules and Plasma Cytokines}

Plasma soluble adhesion molecule levels (E-selectin, ICAM-1, and VCAM-1) were measured with commercially available sandwich ELISAs (Bender MedSystems). Plasma IL-8, IL-10, and transforming growth factor $\beta 1$ (TGF- $\beta 1$ ) levels were measured with commercially available sandwich ELISAs (Pharmingen, BectonDickinson). C-reactive protein (CRP) was measured with an automated rate nephelometry assay (IMMAGE, Beckman).

\section{Statistical Analysis}

All results are expressed as means \pm SEM $(n=10$ patients). Samples were compared with the pre-CPB control. Statistical analysis was performed with robust cluster multiple linear regressions (STATA 7.0, StataCorp).

\section{Results \\ Sampling}

A detailed plasma sampling protocol was undertaken to establish the relative importance of ischemia, reperfusion, and time after $\mathrm{CPB}$ in relation to the CPB inflammatory response (Table 1). Each sample was analyzed for soluble factors, as well as for its effect on the expression of VCAM-1, ICAM-1, and E-selectin by HUVECs. Samples were taken from 10 stable patients undergoing first-time elective $\mathrm{CABG}$ with $\mathrm{CPB}$, with clinical characteristics described in Table 2. Of the 10 patients, one required postoperative adrenaline, and no patients had a high cardiac output-low systemic vascular resistance state.

\section{Time Course of Systemic Inflammation after CPB}

The subjects were first investigated for development of an inflammatory response typical of CPB. Neutrophil counts 

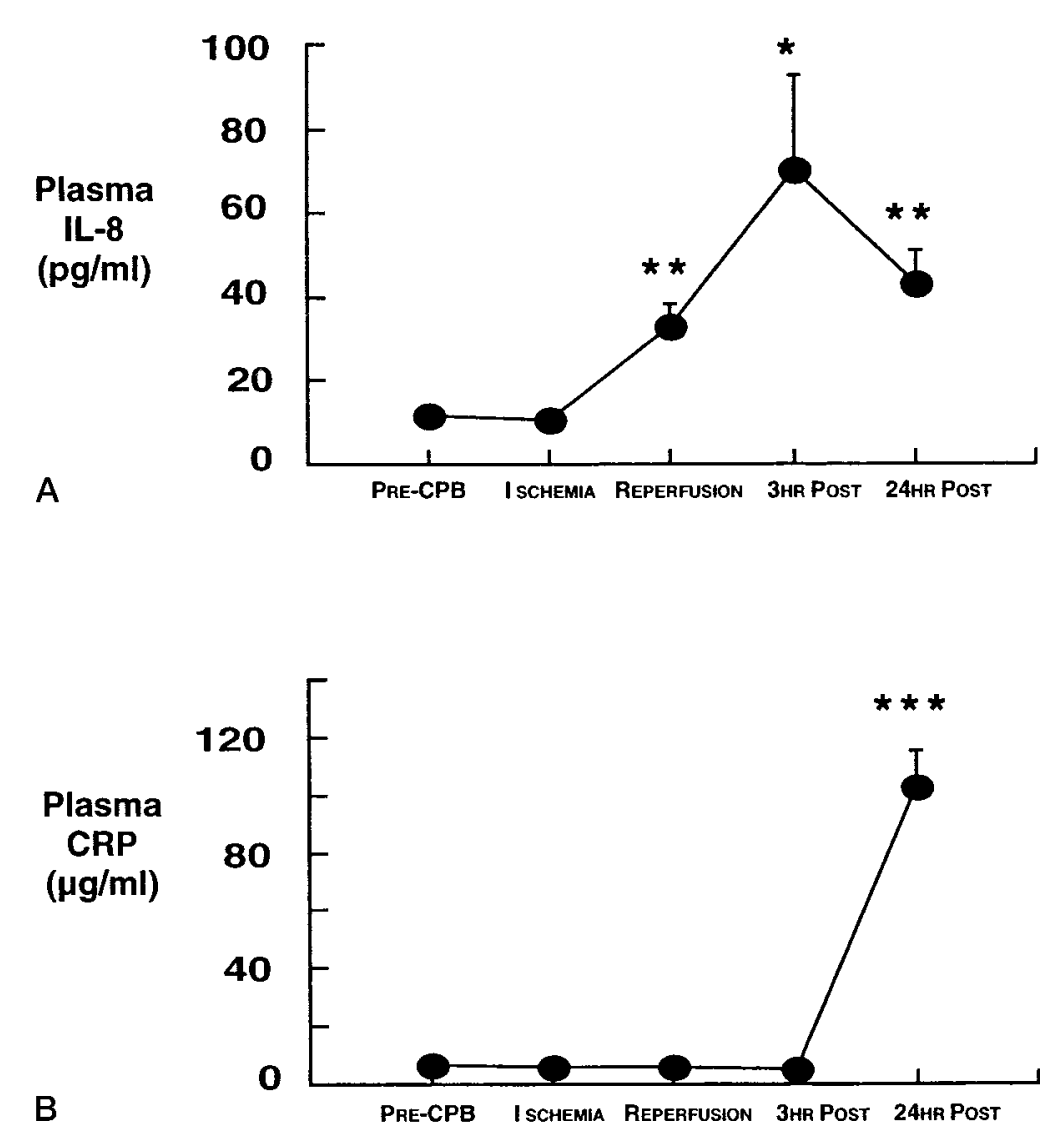

Figure 1. Proinflammatory mediators are increased in circulating plasma after CPB: A, plasma IL-8; B, plasma CRP. Samples are defined in Table 1. ${ }^{*} \boldsymbol{P}<.05,{ }^{* *} \boldsymbol{P}<.01$, and ${ }^{* * *} \boldsymbol{P}<.001$ relative to preoperative values (sample 1). Data are given as means \pm SEM $(n=10)$.

were markedly increased 1 hour postoperatively (preoperatively, $5.2 \pm 0.5 \times 10^{9} / \mathrm{L} ; 1$ hour postoperatively, $12.6 \pm$ $\left.1.1 \times 10^{9} / \mathrm{L} ; P<.001\right)$. Concentrations of the potent neutrophil chemokine IL-8 (Figure 1, A) were significantly increased in the left atrial reperfusate plasma, and postoperative and plasma CRP (Figure 1,B) were increased 24 hours after the operation. Thus plasma IL-8 and neutrophil counts increased in the early post-CPB phase and preceded the increase in CRP.

Soluble ICAM-1 and Soluble VCAM-1, but not Soluble E-selectin, Are Increased Late After CPB Soluble VCAM-1 $(157 \% \pm 18 \%$ relative to before CPB, $P<.0001$; Figure 2, $A)$ and ICAM-1 (135\% $\pm 16 \%, P=$ .02 ; Figure 2, B) were significantly increased 24 hours postoperatively. Soluble VCAM-1 and soluble ICAM-1 were not significantly increased in earlier plasma samples, and their increase occurred later than that of plasma IL-8 and total neutrophil counts, as described above. Soluble E-selectin (an endothelium-specific adhesion molecule; Figure 2, C) was unchanged after the operation.
EC Surface Expression of ICAM-1 and VCAM-1 Are Decreased by Exposure to CPB Plasma

Plasma samples were incubated with HUVECs, and EC expression of VCAM-1, ICAM-1, and E-selectin was quantified to establish whether factors released into plasma during CABG affected EC expression of adhesion molecules.

Relative to control ECs (each subjects' pre-CPB plasma exposed to ECs), EC VCAM-1 expression was decreased when exposed to plasma taken during ischemia and at 3 and 24 hours postoperatively (Figure 3, A). Similarly, ICAM-1 expression was significantly decreased when exposed to plasma taken 3 hours postoperatively (Figure 3, B). Eselectin expression was not significantly affected by exposure to any of the perioperative plasma samples.

\section{Post-CPB Plasma Suppresses IL-1 $\beta$-mediated} Upregulation of VCAM-1 and ICAM-1

The downregulation of HUVEC cell-surface expression of VCAM-1 and ICAM-1 by post-CPB plasma might be due to a deficiency of stimulatory factors or to the presence of factors that actively suppressed expression. ECs were incu- 


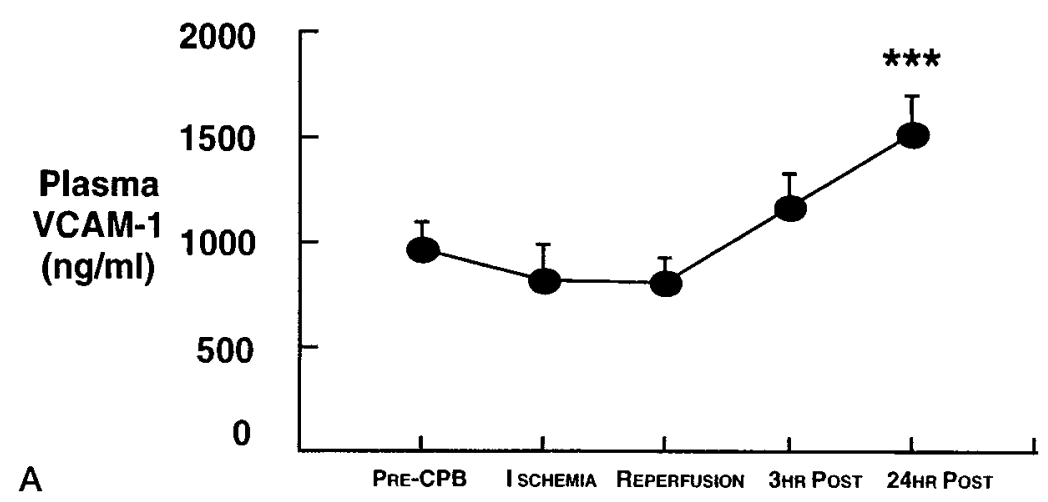

B
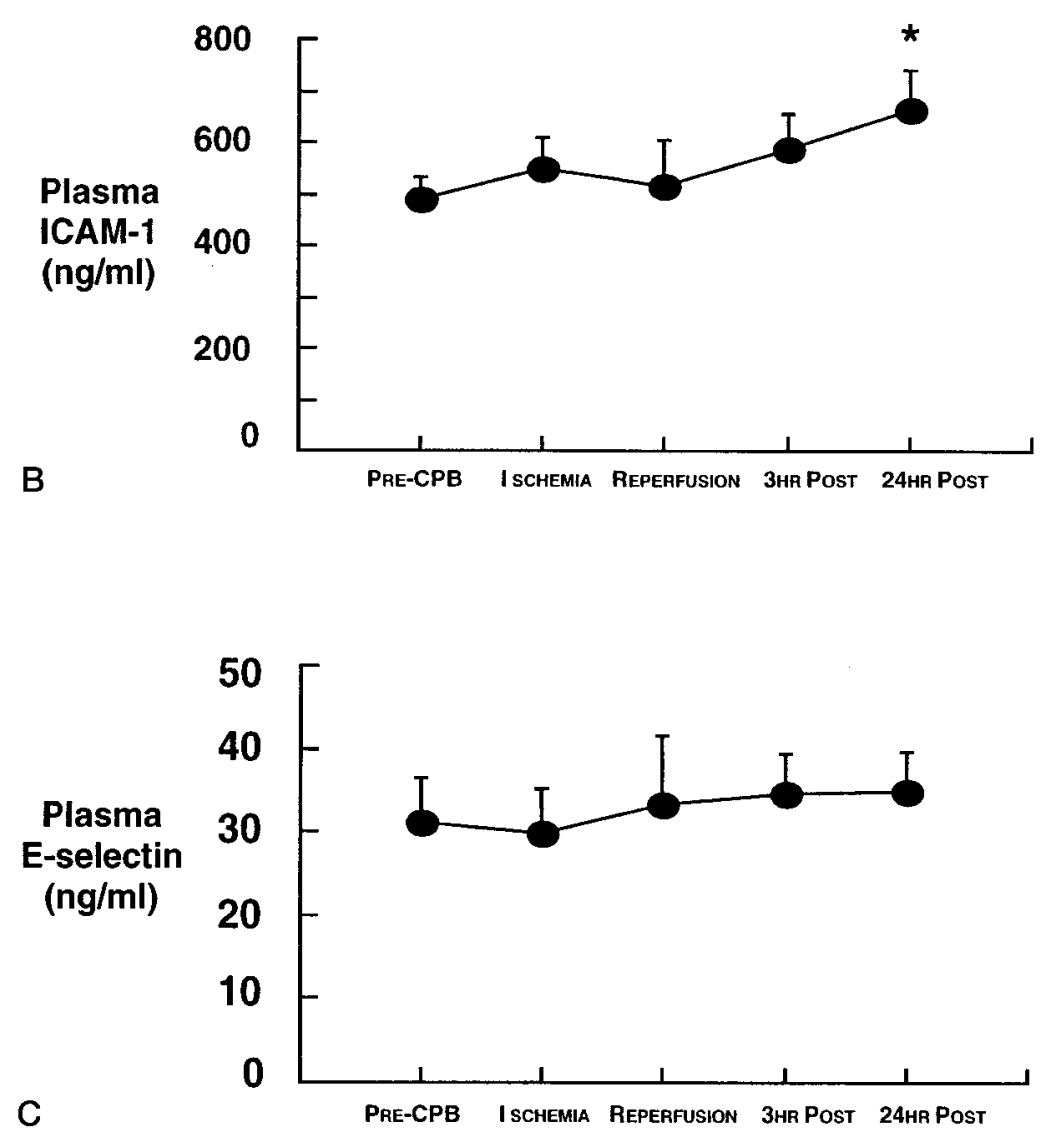

Figure 2. Plasma-soluble VCAM-1 and ICAM-1 increase after CPB: A, VCAM-1; B, ICAM-1; C, E-selectin. Samples are defined in Table 1. ${ }^{* *} P<.01$ and ${ }^{* * *} P<.001$ relative to preoperative values (sample 1). Data are given as means \pm SEM $(n=10)$.

bated with CPB samples in the presence of the proinflammatory cytokine IL- $1 \beta$ to investigate this.

As expected, IL- $1 \beta$ increased cellular expression of Eselectin, ICAM-1, and VCAM-1 by HUVECs by between 3and 6-fold (Figure 4, A). However, the IL-1 $\beta$-mediated increase of VCAM-1 (Figure 4, B) was inhibited by plasma taken 3 hours postoperatively and 24 hours postoperatively. Similarly, the IL- $1 \beta$-mediated increase of ICAM- 1 was inhibited by plasma taken 24 hours postoperatively (Figure $4, C$ ). Expression of E-selectin (Figure $4, D$ ) by IL- $1 \beta$-activated HUVECs was not significantly affected by exposure to any of the patients' plasma samples. Importantly, although the 

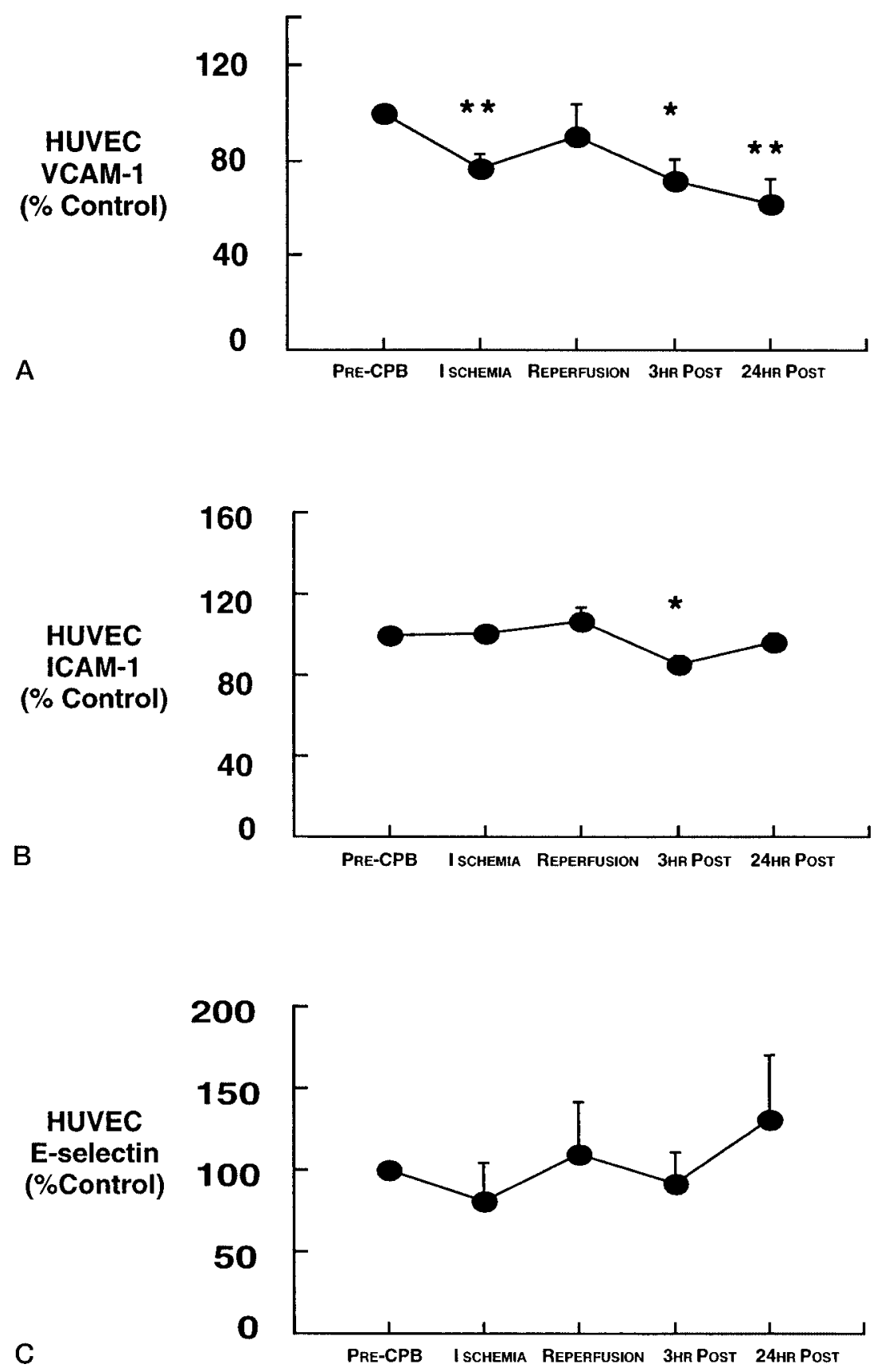

Figure 3. HUVEC cell-surface VCAM-1 and ICAM-1 expression is suppressed by post-CPB plasma. HUVEC monolayers were incubated with CPB plasma. Cellular adhesion molecule expression was quantified by means of ELISA and expressed as a percentage of their expression on HUVECs incubated with pre-CPB plasma of the same subject (sample 1). Samples are defined in Table $1 .{ }^{*} P<.05$ and ${ }^{*} P<.01$ relative to preoperative values (sample 1). Data are given as means $\pm \operatorname{SEM}(n=10)$.

stimulatory effect of IL- $1 \beta$ on ICAM- 1 and VCAM- 1 expression was blunted, IL- $1 \beta$ still exerted a significant stimulatory effect on cellular adhesion molecule expression in the presence of post-CPB plasma. These data indicate that post-CPB plasma might contain factors that actively inhibit IL-1 $\beta$-mediated ICAM- 1 and VCAM- 1 expression.
Plasma TGF- $\beta 1$ and IL-10 Are Increased After CPB Factors known to be capable of actively downregulating EC surface expression of ICAM-1 and VCAM-1 were investigated. TGF- $\beta 1$ and IL- 10 have been identified as inhibitors of EC adhesion molecule expression in many non-CPB states. $^{21,22} \mathrm{We}$ hypothesized that they might contribute to 


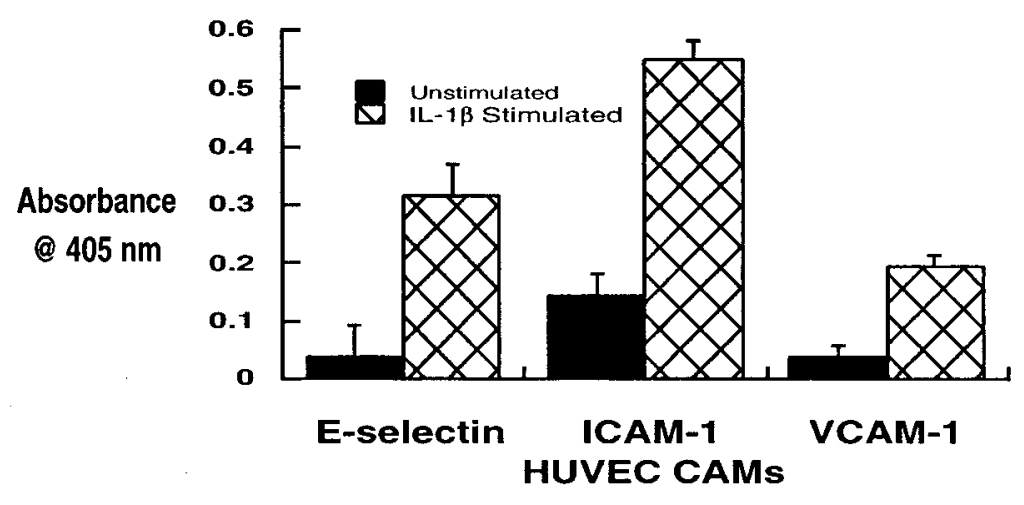

A

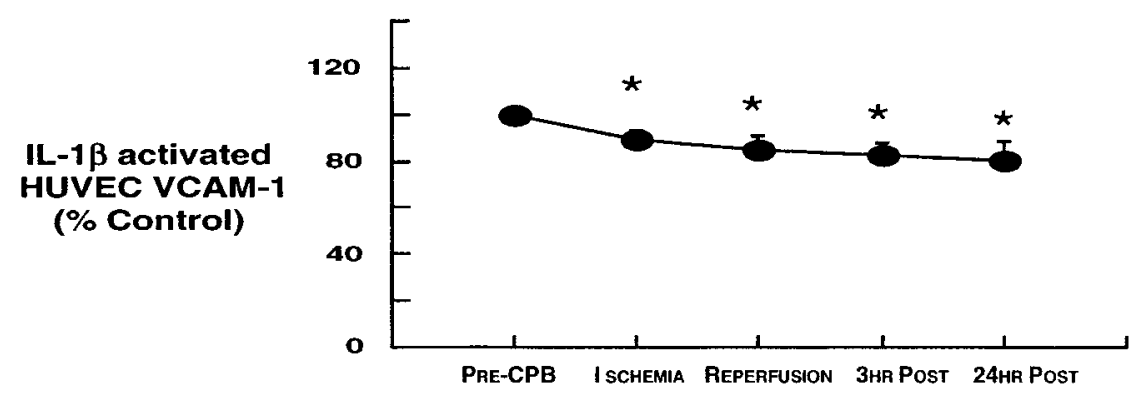

B
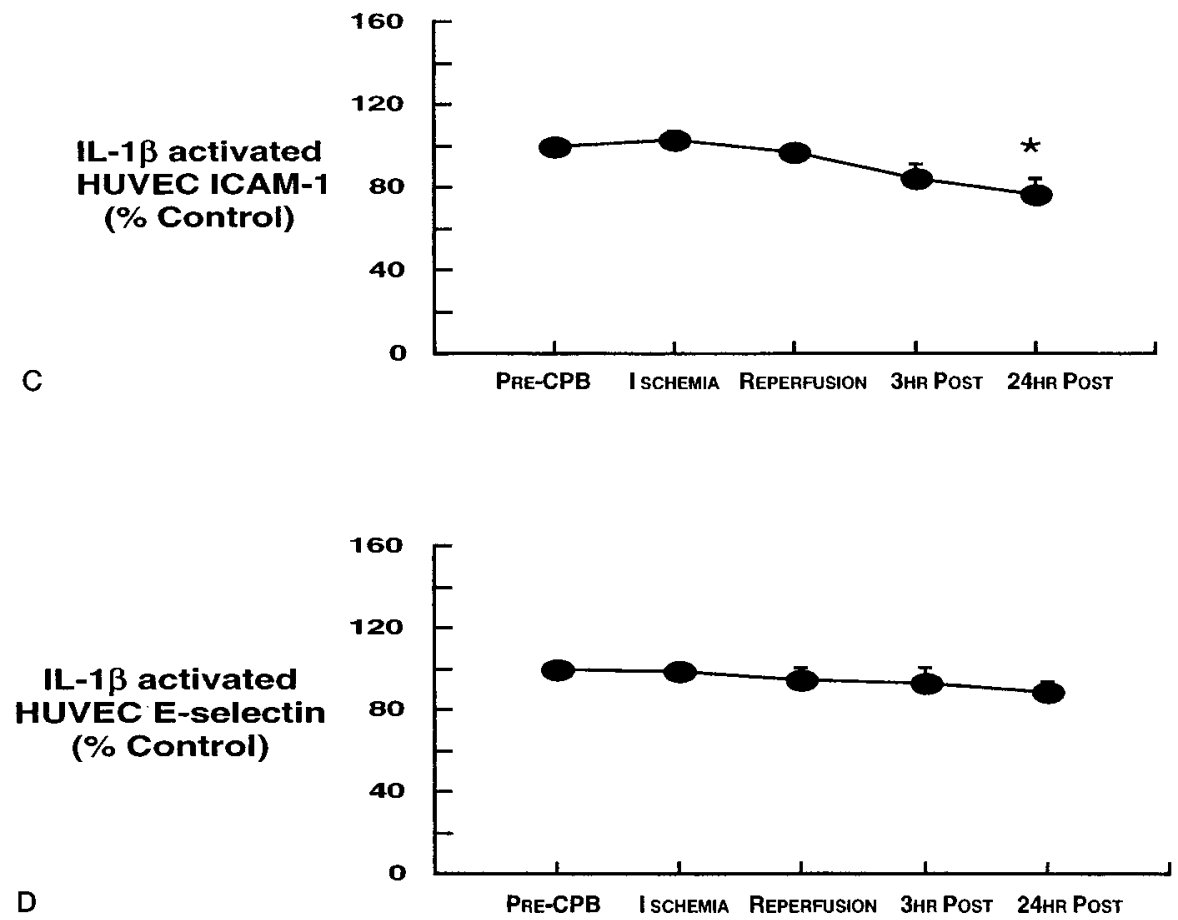

Figure 4. IL-1 $\beta$-activated HUVEC VCAM-1 and ICAM-1 expression is suppressed by post-CPB plasma: A, upregulation of HUVEC expression of VCAM-1, ICAM-1, and E-selectin by IL-1 $\beta$ in the presence of control preoperative plasma ( $P<.001$ for comparison of control with IL-1 $\beta$ for each adhesion molecule); B-D, effect of post-CPB plasma on IL-1 $\beta$-stimulated expression of VCAM-1 (B), ICAM-1 (C), and E-selectin (D). All values are expressed as a percentage expression of IL-1 $\beta$-exposed pre-CPBB plasma (sample 1). Samples are defined in Table 1. ${ }^{*} P<.05$, ${ }^{* *} P<.01$, and ${ }^{* * *} P<.001$ relative to preoperative values (sample 1). Data are given as means $\pm \operatorname{SEM}(\mathrm{n}=10)$. 

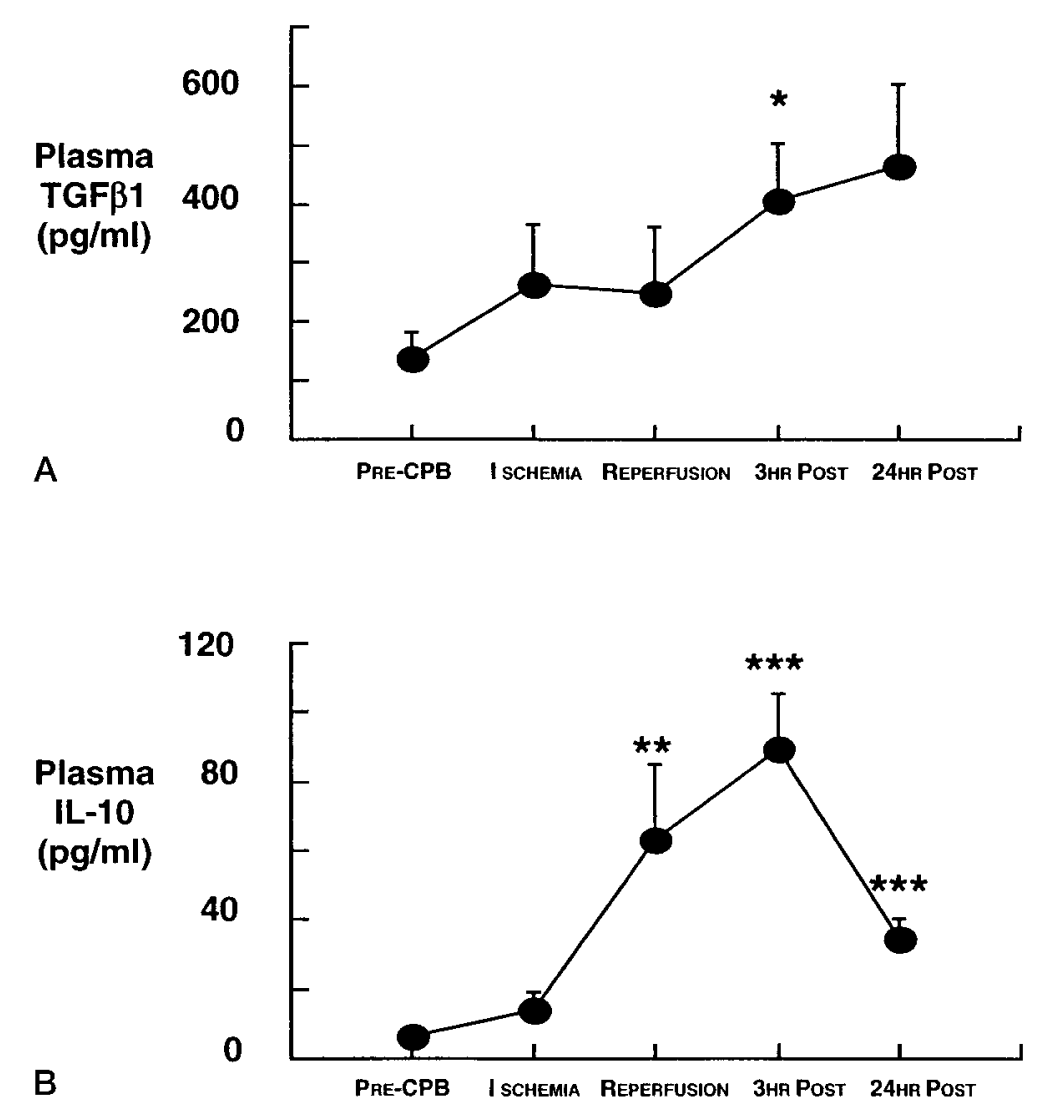

Figure 5. Plasma TGF- $\beta 1$ and IL-10 are increased after CPB: A, TGF- $\beta 1$; B, IL-10. Samples 1 to 5 are defined in Table 1. ${ }^{*} P<.05,{ }^{*} P<.01$, and ${ }^{* *} P<.001$ relative to preoperative values (sample 1). Data are given as means \pm SEM (n=10).

CPB-mediated suppression and investigated this possibility irrespective of whether they were increased after $\mathrm{CPB}$.

TGF- $\beta 1$ at 3 hours was significantly increased 3 hours postoperatively (2.9-fold relative to before CPB; Figure 5, A). IL-10 was significantly increased during CPB after aortic crossclamp release during early reperfusion (9.8-fold) and maximally increased 3 hours postoperatively (14-fold; Figure $5, B)$. The increase of IL-10 was relatively short lived, whereas the TGF- $\beta 1$ increase was sustained.

\section{Discussion}

Inflammation after $\mathrm{CABG}$ is understood to involve activation of the endothelium; however, the relative importance of endothelial expression of cell-surface adhesion molecules in this process is unclear. This study is the first to relate EC expression of adhesion molecules to their concentration in plasma after $\mathrm{CABG}$, and suggests that the two are dissociated.

A number of studies have investigated soluble plasma adhesion molecules after CABG. ${ }^{5-7,23}$ Although some indicate a null effect, ${ }^{8}$ the majority indicate upregulation of soluble adhesion molecules after CPB. ${ }^{5,24}$ Our data supports this in relation to ICAM-1 and VCAM-1, particularly in samples taken 24 hours postoperatively. This was not found for E-selectin.

The difference between ICAM-1, VCAM-1, and E-selectin might indicate that the release of ICAM-1 and VCAM-1 from cells other than endothelium might contribute to plasma soluble adhesion molecules. E-selectin, in contrast to ICAM-1 and VCAM-1, is endothelium specific. Alternatively, the release of E-selectin might be relatively short lived, and time points used in our study might have failed to collect plasma samples containing the highest amounts of E-selectin.

That soluble ICAM-1 and soluble VCAM-1 were increased late after surgical intervention does not suggest their acute release during ischemia or reperfusion during CPB. Other markers of systemic inflammation (polymorphonuclear neutrophil count and IL-8) preceded the soluble ICAM-1 and soluble VCAM-1 increase. These kinetic considerations suggest that if EC activation explains the presence of soluble ICAM-1 and soluble VCAM-1 after CABG, it might follow other inflammatory processes, such as neutrophil activation. Because all patients underwent operations with 
$\mathrm{CPB}$, we cannot delineate the role of the bypass circuit in influencing soluble ICAM-1 and VCAM-1. A comparative study with patients undergoing surgical intervention without CPB would be interesting.

In our study an IL-8 increase preceded postoperative neutrophilia, and this preceded an increase in CRP. This sequence is to be expected because IL-8 is a neutrophil chemokine and CRP represents the later effects of systemic inflammation on the liver. The late increase of CRP suggests ongoing inflammation 24 hours postoperatively, which is consistent with previous literature. ${ }^{25}$ The more rapid decline of IL-10 postoperatively relative to TGF- $\beta 1$ is interesting and unexplained. It suggests that different stimuli (eg, reperfusion injury for IL-10) $)^{22}$ are responsible for upregulation of these 2 inflammatory mediators.

The most remarkable finding in the present study was the suppression of EC ICAM-1 and VCAM-1 expression by post-CABG plasma. This cannot be attributed to an atypical patient population because soluble adhesion molecules and typical systemic inflammatory markers were increased after CABG. The postoperative increase in soluble adhesion molecules and the suppression of EC adhesion molecules might indicate a relationship between the 2 processes. It is possible that soluble adhesion molecules are released from the cell surface as a result of cleavage or shedding ${ }^{26}$ and that their increased plasma concentration represents increased release from the cell surface rather than increased cell expression. Because ICAM-1 and VCAM-1 are constitutively expressed on resting endothelium, and E-selectin expression is induced by activation of the endothelium, our data might support cleavage of cell-surface adhesion molecule rather than increased EC synthesis and cell-surface expression. Alternatively, the increase in soluble adhesion molecules and decreased EC adhesion molecule expression might both be independent consequences of earlier inflammatory processes, such as neutrophil activation and cytokine release. In addition, future studies might identify whether other EC lines, such as microvascular cell lines ${ }^{27}$ or arterial cells, ${ }^{28}$ respond differently to HUVECs when exposed to periCABG plasma. Similarly, it is possible that other adhesion molecules, such as P-selectin, might behave differently than the adhesion molecules in our study.

The blunting of the IL- $1 \beta$-mediated expression of EC ICAM-1 and VCAM-1 (but not E-selectin) suggests that there might be factors released into post-CABG plasma that inhibit ICAM-1 and VCAM-1 expression. One possible mechanism by which plasma antagonizes the effect of $\mathrm{IL}-1 \beta$ is the presence of IL- 1 receptor antagonist, which can be present after CPB. ${ }^{29}$ Second, TGF- $\beta 1$ and IL-10 both suppress adhesion molecule expression ${ }^{30,31}$ and were both increased in our population, which is consistent with a possible role for these cytokines in suppressing EC adhesion molecule expression by post-CPB plasma.
The findings of this study have important clinical implications. First, they dissociate soluble adhesion molecule concentrations from plasma-induced EC expression. Second, they suggest that prevention of EC E-selectin, ICAM-1, or VCAM-1 upregulation might not be a suitable therapeutic target for the reduction of inflammation after CPB. However, inhibition of their expression or activity might still have a role. Third, they suggest that EC activation after $\mathrm{CPB}$ is not an indiscriminate process and that mediators of irreversible leukocyte adhesion (ICAM- 1 and VCAM-1), and not reversible adhesion (E-selectin), are differentially modulated after CPB. Future targeting of the post-CPB systemic inflammatory response will require elucidation of mechanisms underlying these observations.

We thank Gail de Lucia, RN, for her invaluable help in conducting this study and Jack Chen, $\mathrm{PhD}$, for his statistical analyses.

\section{References}

1. Boyle EM Jr, Pohlman TH, Johnson McVerrier ED. Endothelial cell injury in cardiovascular surgery: the systemic inflammatory response. Ann Thorac Surg. 1997;63:277-84.

2. Butthep P, Bunyaratvej A, Funahara Y, Kitaguchi H, Fucharoen S, Sato $\mathrm{S}$, et al. Possible evidence of endothelial cell activation and disturbance in thalassemia: an in vitro study. Southeast Asian J Trop Med Public Health. 1997;28(suppl 3):141-8A.

3. Drake TA, Cheng J, Chang A, Taylor FB Jr. Expression of tissue factor, thrombomodulin, and E-selectin in baboons with lethal Escherichia coli sepsis [published erratum appears in Am J Pathol. 1993; 143:649]. Am J Pathol. 1993;142:1458-70.

4. Heyl W, Handt S, Reister F, Gehlen J, Mittermayer C, Rath W. The role of soluble adhesion molecules in evaluating endothelial cell activation in preeclampsia. Am J Obstet Gynecol. 1999;180:68-72.

5. Blume ED, Nelson DP, Gauvreau K, Walsh AZ, Plumb C, Neufeld EJ, et al. Soluble adhesion molecules in infants and children undergoing cardiopulmonary bypass. Circulation. 1997;96:II352-7.

6. Kalawski R, Bugajski P, Smielecki J, Wysocki H, Olszewski R, More $\mathrm{R}$, et al. Soluble adhesion molecules in reperfusion during coronary bypass grafting. Eur J Cardiothorac Surg. 1998;14:290-5.

7. Boldt J, Kumle B, Papsdorf M, Hempelmann G. Are circulating adhesion molecules specifically changed in cardiac surgical patients? Ann Thorac Surg. 1998;65:608-14.

8. Boldt J, Osmer C, Linke LC, Dapper F, Hempelmann G. Circulating adhesion molecules in pediatric cardiac surgery. Anesth Analg. 1995; 81:1129-35.

9. Ross L, Hassman FMolony L. Inhibition of Molt-4-endothelial adherence by synthetic peptides from the sequence of ICAM-1. J Biol Chem. 1992;267:8537-43.

10. Vallely MP, Bannon PG, Hughes CFL. Endothelial cell adhesion molecules and cardiopulmonary bypass. Asian Cardiovasc Thorac Ann. 2001;9:353-9.

11. Grigg J, Kukielka GL, Berens KL, Dreyer WJ, Entman ML, Smith $\mathrm{CW}$. Induction of intercellular adhesion molecule-1 by lipopolysaccharide in canine alveolar macrophages. Am J Respir Cell Mol Biol. 1994;11:304-11.

12. Maio M, Pinto A, Carbone A, Zagonel V, Gloghini A, Marotta G, et al. Differential expression of CD54/intercellular adhesion molecule-1 in myeloid leukemias and in lymphoproliferative disorders. Blood. 1990;76:783-90.

13. Vanhee D, Molet S, Gosset P, Tillie-Leblond I, Boitelle A, Wallaert B, et al. Expression of leucocyte-endothelial adhesion molecules is limited to intercellular adhesion molecule-1 (ICAM-1) in the lung of pneumoconiotic patients: role of tumour necrosis factor-alpha (TNFalpha). Clin Exp Immunol. 1996;106:541-8. 
14. Freedman AS, Munro JM, Morimoto C, McIntyre BW, Rhynhart K, Lee N, et al. Follicular non-Hodgkin's lymphoma cell adhesion to normal germinal centers and neoplastic follicles involves very late antigen-4 and vascular cell adhesion molecule-1. Blood. 1992;79:20612.

15. Ryan DH, Nuccie BL, Abboud CN, Winslow JM. Vascular cell adhesion molecule-1 and the integrin VLA-4 mediate adhesion of human B cell precursors to cultured bone marrow adherent cells. J Clin Invest. 1991;88:995-1004.

16. Massoudy P, Zahler S, Becker BF, Braun SL, Barankay AMeisner H. Evidence for inflammatory responses of the lungs during coronary artery bypass grafting with cardiopulmonary bypass. Chest. 2001;119: 31-6.

17. Jaffe EA, Nachman RL, Becker CG, Minick CR. Culture of human endothelial cells derived from umbilical veins. Identification by morphologic and immunologic criteria. J Clin Invest. 1973;52:2745-56.

18. Aebert H, Kirchner S, Keyser A, Birnbaum DE, Holler E, Andreesen $\mathrm{R}$, et al. Endothelial apoptosis is induced by serum of patients after cardiopulmonary bypass. Eur J Cardiothorac Surg. 2000;18:589-93.

19. McCrohon JA, Jessup W, Handelsman DJ, Celermajer DS. Androgen exposure increases human monocyte adhesion to vascular endothelium and endothelial cell expression of vascular cell adhesion molecule-1. Circulation. 1999;99:2317-22.

20. Rees D, Sloane T, Jessup W, Dean RT, Kritharides L. Apolipoprotein A-I stimulates secretion of apolipoprotein E by foam cell macrophages. J Biol Chem. 1999;274:27925-33.

21. Opal SM, DePalo VA. Anti-inflammatory cytokines. Chest. 2000;117: 1162-72.

22. Yang Z, Zingarelli B, Szabo C. Crucial role of endogenous interleukin-10 production in myocardial ischemia/reperfusion injury. Circulation. 2000;101:1019-26.
23. Liebold A, Keyl C, Birnbaum DE. The heart produces but the lungs consume proinflammatory cytokines following cardiopulmonary bypass. Eur J Cardiothorac Surg. 1999;15:340-5.

24. Boldt J, Osmer C, Schindler E, Linke LC, Stertmann WAHempelmann G. Circulating adhesion molecules in cardiac operations: influence of high-dose aprotinin. Ann Thorac Surg. 1995;59:100-5.

25. Boralessa H, de Beer FC, Manchie A, Whitwam JG, Pepys MB. $\mathrm{C}$-reactive protein in patients undergoing cardiac surgery. Anaesthesia. 1986;41:11-5.

26. Leeuwenberg JF, Smeets EF, Neefjes JJ, Shaffer MA, Cinek T, Jeunhomme TM, et al. E-selectin and intercellular adhesion molecule-1 are released by activated human endothelial cells in vitro. Immunology. 1992;77:543-9.

27. Frigerio S, Gelati M, Ciusani E, Corsini E, Dufour A, Massa G, et al. Immunocompetence of human microvascular brain endothelial cells: cytokine regulation of IL-1beta, MCP-1, IL-10, sICAM-1 and sVCAM-1. J Neurol. 1998;245:727-30.

28. Kalogeris TJ, Kevil CG, Laroux FS, Coe LL, Phifer TJ, Alexander JS Differential monocyte adhesion and adhesion molecule expression in venous and arterial endothelial cells. Am J Physiol. 1999;276:L9-19.

29. Marie C, Muret J, Fitting C, Payen D, Cavaillon JM. Interleukin-1 receptor antagonist production during infectious and noninfectious systemic inflammatory response syndrome. Crit Care Med. 2000;28: 2277-82.

30. Morise Z, Eppihimer M, Granger DN, Anderson DC, Grisham MB Effects of lipopolysaccharide on endothelial cell adhesion molecule expression in interleukin-10 deficient mice. Inflammation. 1999;23: 99-110.

31. Gamble JR, Khew-Goodall Y, Vadas MA. Transforming growth factor-beta inhibits E-selectin expression on human endothelial cells. J Immunol. 1993;150:4494-503.

\section{Bound volumes available to subscribers}

Bound volumes of The Journal of Thoracic and Cardiovascular Surgery are available to subscribers (only) for the 2002 issues from the Publisher, at a cost of $\$ 134.00$ for domestic, $\$ 165.85$ for Canadian, and $\$ 155.00$ for international subscribers for Vol 123 (January-June) and Vol 124 (July-December). Shipping charges are included. Each bound volume contains a subject and author index and all advertising is removed. The binding is durable buckram with the Journal name, volume number, and year stamped in gold on the spine. Payment must accompany all orders. Contact Mosby, Subscription Customer Service, 6277 Sea Harbor Dr, Orlando, FL 32887, USA; phone 800-654-2452 or 407-345-4000.

Subscriptions must be in force to qualify. Bound volumes are not available in place of a regular Journal subscription. 